\title{
Pendidikan Karakter Berbasis Local Wisdom (studi kasus di TK Islam PAS Munqidzatun Nasyi’ah Desa Wilangan Kecamatan Sambit Kabupaten Ponorogo)
}

\author{
Tamrin Fatoni \\ Institut Agama Islam Sunan Giri (INSURI) Ponorogo
}

\begin{abstract}
Developing powerful communications technology has created unlimited free communication. The negative impact of this phenomenon is when a culture that is not good from the outside is swallowed out by children who are still young. As a result, it will easily experience cultural dislocation. One of the legacies of local wisdom that are not interested in the midst of the community is the Javanese dolanan song. Therefore all efforts must be sought from the very beginning. These efforts can be done through various ways, including habituation of children to play and sing songs (songs) dolanan Javanese, which actually contains a lot of character values.

This study included a descriptive study, a case study at PAS Munqidzatun Nasyi'ah Wilangan Islamic Kindergarten. This study aims to describe; 1 . Describe the form of character education in PAS Munqidzatun Nasyi'ah Wilangan Islamic Kindergarten. 2. Describe the strategy for implementing character education in PAS Munqidzatun Nasyi'ah Wilangan Islamic Kindergarten. 3. Describe the results of character education in PAS Munqidzatun Nasyi'ah Wilangan Islamic Kindergarten. This research includes field research using a qualitative approach. In collecting data, the author uses the method of interviews, observation, and documentation as a data collection technique. The technique chosen in data analysis is data reduction, data display and conclusions or verification.

From this study it can be seen that: 1 . the form of character education in PAS Islamic Kindergarten Munqidzatun Nasyi'ah Wilangan is a local widom-based character education (local wisdom) in the form of Javanese dolanan songs. There are three dolanan songs used for character planting, namely Sluku-sluku Bathok, gundul-gundul Pachol and Menthok-menthok. 2. The strategy for the implementation of character education in PAS Islamic Kindergarten Munqidzatun Nasyi'ah Wilangan is to use reflective methods. This can be proven by giving an explanation of moral values to students, after the song is finished the song is sung both in class before the core lesson begins or while playing outside the classroom. 3. The results of character education at PAS Islam Munqidzatun Nasyi'ah Wilangan Kindergarten have fulfilled the values of the basic characters, namely: a. Respectful and polite character through greeting each other and shaking hands. $b$. This character of independence and responsibility can be seen from throwing garbage in its place.
\end{abstract}

\footnotetext{
Abstrak

Perkembangan teknologi komunikasi yang sangat pesat telah menciptakan komunikasi bebas tanpa batas. Dampak negatif dari fenomena ini adalah ketika budaya yang kurang baik dari luar ditelan mentah-mentah oleh anak-anak yang masih usia dini. Akibatnya, dengan mudah akan mengalami peristiwa ketercerabutan budaya. Salah satu warisan kearifan lokal yang mulai tidak diminati ditengah-tengah masyarakat adalah tembang dolanan Jawa. Maka dari itu segala usaha harus diupayakan dari sejak dini. Upaya tersebut dapat dilakukan melalui berbagai cara, antara lain pembiasaan anak untuk bermain dan menyanyikan lagu-lagu (tembang) dolanan Jawa, yang sebenarnya didalamnya banyak mengandung nilai-nilai karakter.

Penelitian ini termasuk penelitian deskriptif, studi kasus di TK Islam PAS Munqidzatun Nasyi'ah Wilangan. Penelitian ini bertujuan mendeskripsikan: (1) Mendiskripsikan bentuk pendidikan karakter di TK Islam PAS Munqidzatun Nasyi'ah Wilangan, (2) Mendiskripsikan strategi implementasi pendidikan karakter di TK Islam PAS Munqidzatun Nasyi'ah Wilangan, dan (3) Mendiskripsikan hasil pendidikan karakter di TK Islam PAS Munqidzatun Nasyi'ah Wilangan. Penelitian ini termasuk penelitian lapangan dengan menggunakan pendekatan kualitatif.
} 
Dalam pengumpulan data, penulis menggunakan metode wawancara, observasi, dan dokumentasi sebagai teknik pengumpulan datanya. teknik yang dipilih dalam analisis data adalah reduksi data, display data dan pengambilan kesimpulan atau verifikasi.

Dari penelitian ini dapat diketahui bahwa: (1) Bentuk pendidikan karakter di TK Islam PAS Munqidzatun Nasyi'ah Wilangan adalah pendidikan karakter berbasis local widom (kearifan lokal) berupa tembang dolanan Jawa. Ada tiga tembang dolanan yang dipakai untuk penanaman karakter yaitu, Sluku-sluku Bathok, gundul-gundul Pachol dan Menthok-menthok, (2) Strategi implementasi pendidikan karakter di TK Islam PAS Munqidzatun Nasyi'ah Wilangan adalah menggunakan metode reflektif. Hal ini dapat dibuktikan dengan adanya pemberikan penjelasan nilai-nilai moral kepada para siswa, setelah selesai tembang dolanan dinyanyikan baik didalam kelas sebelum pelajaran inti dimulai maupun sambil bermain ditempat luar kelas, dan (3) Hasil pendidikan karakter di TK Islam PAS Munqidzatun Nasyi'ah Wilangan sudah memenuhi niainilai karakter dasar yaitu: (a) Karakter hormat dan santun melalui saling mengucap salam dan berjabat tangan, dan (b) Karakter kemandirian dan tanggung jawab ini bisa dilihat dari membuang sampah pada tempatnya.

Keywords: Pendidikan, Karakter, Local Wisdom

\section{PENDAHULUAN}

Perkembangan teknologi komunikasi yang sangat pesat telah menciptakan komunikasi bebas lintas benua, lintas negara. Dampak negatif dari fenomena ini adalah ketika budaya yang kurang baik dari luar ditelan mentah-mentah oleh anak-anak yang masih usia dini. Akibatnya, dengan mudah seseorang (utamanya generasi muda) akan mengalami peristiwa ketercerabutan budaya sehingga menciptakan budayanya sendiri. Hal itu terjadi karena selain tidak lagi mengenal budaya asli nenek moyangnya, juga belum mampu memilih dan memilah, mana budaya yang baik sesuai karakter bangsanya. ${ }^{1}$

Salah satu warisan kearifan lokal yang mulai hilang ditengah-tengah masyarakat adalah tembang dolanan Jawa. Anak-anak lebih menyukai permainan modern daripada permainan tradisional. Sehingga lagu-lagu yang terdapat dalam permainan tersebut juga jarang didendangkan. Keadaan seperti ini akan mengakibatkan punahnya lagu-lagu tersebut. Padahal lagu-lagu tersebut mengandung makna yang mampu mempengaruhi pembetukan karakter mereka. Karena salah satu metode untuk mengembangkan pendidikan karakter adalah dengan bernyanyi.

Bernyanyi adalah kegiatan musik yang fundamental, karena anak dapat

\footnotetext{
${ }^{1}$ James P. Spradley, The Etnographic Interview Terj. (Yogyakarta: PT Tiara Wacana, 2007), 15.
} 
mendengar melalui inderanya sendiri; menyuarakan beragam tinggi nada dan irama musik dengan suaranya sendiri. Lagu yang dinyanyikanpun harus sesuai dengan perkembangan anak, karena melalui nyanyian anak yang sesuai, anak dapat (1) Menambah perbendaharaan bahasa, kreatif, berimajinasi (segi intelegensi); (2) Bermain bersama, mematuhi aturan permainan, tidak mementingkan diri sendiri (segi sosial); (3) Menyalurkan emosi, menimbulkan rasa senang (segi emosi); dan (4) Melatih otot badan, mengkoordinasikan gerak tubuh (segi psikomotorik).

Maka dari itu masalah besar yang tidak boleh diremehkan dan dibiarkan serta segala usaha harus diupayakan dari sejak dini agar generasi penerus bangsa dapat tumbuh menjadi manusia yang berkarakter baik dan terpuji. Upaya tersebut dapat dilakukan melalui berbagai cara, antara lain pembiasaan anak untuk bermain dan menyanyikan lagu-lagu (tembang) dolanan Jawa, yang banyak mengandung nilai-nilai didaktis yang bersumber pada filsafat budaya Jawa yang adiluhung, yang mengajarkan nila-nilai kebaikan, dan budi pekerti luhur dan mulia.

TK Islam PAS Munqidzatun Nasyi'ah Wilangan adalah salah satu lembaga pendidikan anak usia dini yang mempunyai mempunyai keunikan dan karismatik tersendiri yang membedakan dengan lembaga pendidikan anak usia dini lain di daerah sekitarnya. Yakni; merupakan lembaga pendidikan anak usia dini yang bercorakkan Islam akan tetapi masih menyeimbangkan nilai-nilai Religi (al-Qur'an dan hadits) serta menjaga nilai kearifan lokal (Local Wisdom).

Berdasarkan penjajakan awal di lapangan, bahwasanya TK Islam PAS Munqidzatun Nasyi'ah Wilangan masih melestarikan lokal (Local Wisdom) dengan mengajarakan tembang dolanan Jawa pada siswa-siswinya. Dengan sebuah argumen bahwa tembang dolanan Jawa banyak mengandung nilai-nilai didaktis yang bersumber pada filsafat budaya Jawa yang adiluhung, yang mengajarkan nila-nilai kebaikan, dan budi pekerti luhur dan mulia.

Berangkat dari permasalahan ini penulis tertarik untuk melakukan penelitian yang berjudul Pendidikan Karakter Berbasis Local Wisdom (studi kasus di TK Islam PAS Munqidzatun Nasyi'ah Wilangan Desa Wilangan 
Kecamatan Sambit Kabupaten Ponorogo).

\section{Metode Penelitian}

Pendekatan yang peneliti gunakan dalam penelitian ini adalah menggunakan penelitian kualitatif. Jenis penelitian yang peneliti lakukan adalah studi kasus penelitian lapangan (field research) dapat juga dianggap sebagai pendekatan luas dalam penelitian kualitatif. Sumber data adalah informan yang terdiri dari: kepala TK, beberapa guru dan siswa TK Islam PAS Munqidzatun Nasyi'ah. Teknik pengumpulan data dalam penelitian ini menggunakan wawancara, observasi dan dokumentasi. Sebab bagi peneliti kualitatif, fenomena dapat dimengerti maknanya dengan baik, apabila dilakukan interaksi dengan subyek melalui wawancara mendalam, dan observasi pada latar dimana fenomena tersebut berlangsung

\section{Hasil dan Pembahasan}

\section{Pendidikan Karakter}

Dalam Undang-Undang Nomor 20 Tahun 2003 tentang Sistem Pendidikan Nasional dalam Pasal 1 ayat (1) disebutkan bahwa pendidikan adalah usaha sadar dan terencana untuk mewujudkan suasana belajar dan proses pembelajaran agar anak didik secara aktif mengembangkan potensi dirinya untuk memiliki kekuatan spiritual keagamaan, pengendalian diri, kepribadian, kecerdasan, akhlak mulia, serta keterampilan yang diperlukan dirinya, masyarakat, bangsa dan negara. ${ }^{2}$

Secara Istilah karakter secara harfiah berasal dari bahasa Latin Charakter, yang antara lain berarti: watak, tabiat, sifat-sifat kejiwaan, budi pekerti, kepribadian atau akhlak. Sedangkan secara istilah, karakter diartikan sebagai sifat manusia pada umumnya dimana manusia mempunyai banyak sifat yang tergantung dari faktor kehidupannya sendiri.

Sedangkan menurut Thomas Lickona mendefinisikan orang yang berkarakter sebagai sifat alami seseorang dalam merespon situasi secara bermoral

${ }^{2}$ UU RI Tahun 2005, Tentang Guru dan Dosen serta UU RI No. 20 Tahun 2003 tentang Sisdiknas, 74. 
yang dimanifestasikan dalam tindakan nyata melalui tingkah laku yang baik, jujur, bertanggung jawab, menghormati orang lain, dan karakter mulia lainnya. Pengertian ini mirip dengan apa yang diungkapkan oleh Aristoteles bahwa karakter itu erat kaitannya dengan habit atau kebiasaan yang terus menerus dilakukan. Lebih jauh, Lickona menekankan tiga hal dalam mendidik karakter. Menurutnya keberhasilan pendidikan karakter dimulai dengan pemahaman karakter yang baik, mencintainya, dan pelaksanaan atau peneladanan atas karakter baik itu. ${ }^{3}$

\section{Metode Implementasi Pendidikan Karakter}

Adapun metode dalam mengimplementasikan pendidikan karakter menurut Noeng Muhadjir pendidikan karakter atau nilai dapat diselengarakan menggunakan metode dogmatis, metode deduktif, metode induktif dan metode reflektif. ${ }^{4}$ Adapun pengertian beberapa metode tersebut sebagai berikut:

1. Metode dogmatis, yaitu metode untuk mengajarkan nilai kepada peserta didik dengan jalan menyajikan nilai-nilai kebaikan dan kebenaran yang harus di terima apa adanya tanpa mempersoalkan hakikat kebaikan dan kebenaaran itu sendir.

2. Metode deduktif, yaitu cara menyajikan nilai-nilai kebenaran (keutuhan dan kemanusiaan) dengan jalan menguraikan konsep tentang kebenaran itu agar dipahami peserta didik. Metode ini bertolak dari kebenaran sebagai teori atau konsep yang memiliki nilai-nilai baik, selanjutnya ditarik beberapa contoh kasus terapan dalam kehidupan sehari-hari di mayarakat atau ditarik kedalam nilai-nilai yang lebih khusus atau sempit ruang lingkupnya.

3. Metode induktif yaitu, membelajarkan nilai dimulai dengan mengenalkam kasus-kasus dalam kehidupan sehari-hari kemudian ditarik maknanya secara hakiki tentang nilai-nilai kebenaran.

3 Lickona Thomas, Educating For Character: How Our School Can Teach Respect and Responsibility (New York: Bantam Books, 1992), 22.

${ }^{4}$ Zubaedi, Desain Pendidikan Karakter: Konsepsi dan Aplikasinya dalam Dunia Pendidikan (Jakarta: Kencana, 2011), hlm. 231-232. 
4. Metode reflektif yaitu, gabungan dari metode induktif dan deduktif. Yakni mebelajarkan nilai dengan jalan memberikan konsep secara umum tentang nilai-nilai kebenaran kemudian melihatnya dalam kasus sehari-hari atau melihat dari kasus-kasus sehari-hari di kembalikan dalam kasus-kasus teoritisnya secara umum.

\section{Tahapan Pendidikan Karakter.}

Karakter manusia terbentuk melalui lima tahap yang saling berkaiatan. Lima tahp itu adalah:

a. Adanya nilai yang diserap seorang darai berbagai sumber, seperti agama, ideologi, pendidikan dan sebagainya.

b. Nilai membentuk pola pikir seseorang yang secara keseluruhan keluar dalam bentuk rumus visi.

c. Visi turun kewilayah hati membentuk suasana jiwa yang secara keseluruhan membentuk mentalitas.

d. Mentalitas mengalir memasuki wilayah fisik dan melahirkan tindakan yang secara keseluruhan sdisebut sikap.

e. Sikap-sikap dominan dalam diri seseorang yang secara keseluruhanmencitrai dirinya adalah apa yang disebut sebagai karakter atau kepribadian. ${ }^{5}$

\section{Tujuan Pendidikan Karakter}

Pada dasarnya Pendidikan karakter bertujuan untuk meningkatkan mutu penyelenggaraan dan hasil pendidikan yang mengarah pada pencapaian pembentukan karakter atau akhlak mulia peserta didik secara utuh, terpadu, dan seimbang, sesuai standar kompetensi lulusan. Melalui pendidikan karakter diharapkan peserta didik mampu secara mandiri meningkatkan dan menggunakan pengetahuannya, mengkaji dan menginternalisasi serta mempersonalisasi nilainilai karakter dan akhlak mulia sehingga terwujud dalam perilaku sehari-hari.

\footnotetext{
${ }^{5}$ Muslih Masnur, Pendidikan Karakter Menjawab Tantangan Krisis Multidimensional (Jakarta: Bumi Aksara, 2003), 29.
} 
Hal ini sesuai dengan rumusan tujuan pendidikan nasional yang terdapat pada UUSPN No.20 tahun 2003 Bab 2 pasal 3: Pendidikan Nasional berfungsi mengembangkan kemampuan dan membentuk watak serta peradaban bangsa yang bermartabat dalam rangka mencerdaskan kehidupan bangsa, bertujuan untuk berkembangnya potensi anak didik agar menjadi manusia yang beriman dan bertakwa kepada Tuhan Yang Maha Esa, berakhlak mulia, sehat, berilmu, cakap, kreatif, mandiri, dan menjadi warga negara yang demokratis serta bertanggung jawab.

\section{Nilai-nilai Pendidikan Karakter}

Menurut Ratna Megawangi menyebutkan ada sembilan nilai karakter yang perlu ditanamkan kepada peserta didik, yaitu: (a) Cinta Tuhan dan segenap ciptaan-Nya (love Allah, trust, reverevce, loyalty); (b) Kemandirian dan tanggung jawab (responsibility, excellence, self relience, discipline, orderliness); (c) Kejujuran/Amanah, Bijaksana (trustworthiness, reliability, honesty) (d) Hormat dan santun (respect, courtessy, obidience); (e) Dermawan, suka menolong dan gotong royong (love, compassion, caring, empathy, generousity, moderation, cooperetion); (f) Percaya diri, kreatif dan pekerja keras (confidence, assertiveness, creativity, resourcefulness, conrage, determination and enthusiasm); (g) Kepernimpinan dan keadilan (justice, fairness, mercy, leadership); (h) Baik dan rendah hati (kindness, friendness, humility, modesty); dan (i) Toleransi dan kedamaian dan kesatuan (tolerance, flexibility, feacefulness, unity). ${ }^{6}$

\section{Tembang Jawa.}

Dalam istilah bahasa Jawa tembang berarti lagu. Tembang juga disebut dengan istilah sekar, sebab tembang memang berasal dari kata kembang mempunyai persamaan makna dengan kata sekar, atau bunga. Dalam pengertian

\footnotetext{
${ }^{6}$ Ratna Megawangi, Pendidikan Karakter..., 95.
} 
lain, tembang adalah lirik atau sajak yang mempunyai irama nada sehingga dalam bahasa Indonesia biasa disebut sebagai lagu. ${ }^{7}$

\section{Ciri-ciri Tembang Dolanan}

Ciri penting terkait dengan lagu dolanan anak adalah (1) bahasanya sederhana, (2) menggunakan cengkok sederhana, (3) jumlah baris terbatas, (4) berasi hal-hal yang selaras dengan keadaan anak, dan memuat hal-hal yang menghibur dan kebersamaan. ${ }^{8}$

\section{Analisis Bentuk Pendidikan Karakter di TK Islam PAS Munqidzatun Nasyi'ah Wilangan}

Mencermati tentang bentuk pendidikan karakter di TK Islam PAS Munqidzatun Nasyi'ah Wilangan, yaitu dengan berbasis local widom (kearifan lokal) berupa tembang dolanan Jawa. Bentuk pendidikan karakter tersebut apabila dikaji dengan ciri penting terkait dengan lagu dolanan anak, yaitu:

1. Bahasanya sederhana

2. Menggunakan cengkok sederhana

3. Jumlah baris terbatas

4. Berisi hal-hal yang selaras dengan keadaan anak

5. Memuat hal-hal yang menghibur dan kebersamaan. ${ }^{9}$

Dilihat dari beberapa ciri tersebut tembang dolanan Jawa merupakan sebuah bentuk sarana penanaman pendidikan karakter yang cocok dengan dunia anak karena ciri yang selaras dengan keadaan anak dan memuat hal-hal yang menghibur serta kebersamaan hal tersebut akan lebih mudah untuk diterima anak dalam penanaman karakter.

Beberapa tembang dolanan Jawa yang diajarkan di TK Islam PAS Munqidzatun Nasyi'ah Wilangan yang didalamnya mengandung ajaran kebaikan dan budi pekerti yang muia:

${ }^{7}$ Tri Agung Hariyanta, Kamus Kebahasaan dan Kesusastraan, (Surakata: Aksara Sinergi Media, 2012), 217.

${ }^{8}$ Suwardi Endraswara, Tradisi Lisan Jawa, (Yogyakarta: Laksbang Presindo, 2005), 101.

${ }^{9}$ Ibid. 


\section{Sluku-sluku Bathok}

a. Sluku-sluku bathok, bathoke ela-elo (ayun-ayun kepala, kepalanya geleng geleng) memiliki makna bahwa manusia harus selalu ingat kepada Sang penciptanya dengan cara berdzikir untuk menganggungkan asma-Nya.

b. Si Rama menyang Sala, oleh-olehe payung motha Si Rama menyang Sala, oleh-olehe payung motha (si bapak pergi ke Sala, oleh-olehnya payung mutha) memiliki makna bahwa manusia secara fitrahnya memikul tanggung jawab untuk mencari nafkah di dunia. Mencari nafkah merupakan salah satu bentuk ibadah. Manusia dapat menggunakan harta bendanya untuk beribadah di jalan Allah.

c. Mak jenthit lolo lobah, wong mati ora obah (secara tiba-tiba begerak, orang mati tidak bergerak) memiliki makna bahwa orang yang mati sudah terputus hubungannya dengan urusan duniawi. Harta yang diperoleh semasa hidupnya kelak.

d. Nek obah medeni bocah, nek urip goleka dhuwit Nek obah medeni bocah, nek urip goleka dhuwit (kalau bergerak menakuti orang, kalau hidup carilah uang) memiliki makna bahwa ketika manusia mati hanya membawa amalannya ketika di dunia, keluarga maupun harta benda tidak akan menemaninya, hanya amalan-amalan baiknya saja yang akan menemani.

2. Menthok-menthok tak kandhani

a. Menthok-menthok tak kandhani (Menthok-menthok saya nasehati) memiliki makna bahwa sebagai seorang manusia harus mau mendengarkan nasehat dari orang lain. Entah nasehat tersebut berguna untuk dirinya dan membawa kebaikan pada dirinya harus diterima. Manusia secara alamiah dilahirkan ke dunia sebagai makhluk individu dan mahkluk sosial. Secara kodrati manusia akan banyak berinteraksi dengan orang lain.

b. Mung solahmu angisin-isini (Hanya perilakumu yang memalukan) memiliki makna bahwa manusia dapat membuat perilaku yang memalukan baik dilingkungan keluarga ataupun lingkungan 
masyarakat. Perilaku ini dapat tercermin ketika membawakan dirinya di lingkungan masyarakat maupun umum. Perilaku yang tidak baik akan membuat malu diri sendiri dan orang lain.

c. Bokya aja ndheprok (Jangan hanya diam dan duduk) memiliki makna tentang kemalasan seseorang yang tidak memiliki aktivitas sehingga tidak memiliki manfaat bagi orang lain. Kemalasan akan membawa keburukan bagi dirinya dan keluarganya, bahkan bagi negaranya.

d. Ana kandhang wae (di kandang saja) memiliki makna tentang sindiran kepada manusia yang hanya di rumah tanpa ada aktivitas yang berguna bagi orang lain. Seseorang yang hanya diam di rumah biasanya menjadi kurang pergaulan. Dari kurangnya pergaulan ini mengakibatkan tidak adanya pengalaman sehingga kurang memiliki wawasan yang luas. Biasanya orang yang malas bersilaturahmi ke orang lain biasanya akan jauh dari rejeki.

e. Enak-enak ngorok (enak-enak mendengkur) memiliki makna tentang seseorang yang memiliki sifat malas bekerja. Biasanya orang seperti biasa memiliki kebiasaan suka tidur tidak tepat pada waktunya. Hampir semua waktunya digunakan untuk tidur. Kebiasaan ini akan berakibat pada kemalasan.

f. Ora nyambut gawe (tidak bekerja) memiliki makna orang tidak memiliki pekerjaan. Manusia memiliki itrah sendirinya pada waktu siang hari untuk bekerja sedangkan waktu malam digunakan untuk beribadah dan beristirahat. Seorang laki-laki memiliki kewajiban untuk mencari nafkah dengan bekerja. Bekerja juga merupakan sebuah bentuk ibadah.

g. Menthok-menthok (menthok-menthok) memiliki makna untuk menyebut salah satu nama hewan. Hewan ini terkenal dengan sifat pemalasnya. Jadi jika manusia memiliki sifat pemalas maka dapat disamakan hewan menthok-menthok (sejenis unggas).

h. Mung lakumu megal-megolgawe guyu (hanya jalanmu meggoyangkan pantat membuat orang tertawa) memiliki makna bahwa orang pemalas 
biasanya hanya memiliki satu pekerjaan yaitu tidur. Biasanya orang seperti ini memiliki badan yang gemuk (tidak ideal) sehingga cara jalannya pun seperti menthok (hewan sejenis unggas).

3. Gundhul gundhul pacul.

Makna pendiikan karakter yang terdapat pada tembang gundulgundul pacul adalah fungsi pendidikan, yaitu menggambarkan seorang anak yang gundul, nakal, bandel, angkuh, dan tidak bertanggung jawab. Dia tidak dapat membedakan hal-hal yang baik dan buruk. Dia beranggapan bahwa dirinya orang yang paling benar, paling bisa, dan paling pintar. Sehingga dia bersikap gembelelengan, sombong, dan tak tahu diri. Apabila dipercaya untuk memegang amanah yang menyangkut kehidupan orang banyak, dia tetap bersikap tidak peduli. Akibat dari kesombongan dan keangkuhannya itu maka kesejahteraan dan keadilan yang semestinya berhasil akhirnya menjadi hancur berantakan. Dari syair tembang tersebut mengandung makna tidak boleh sombong, dalam hal ini terlihat bahwa orang yang sombong, angkuh, dan ceroboh akan membawa kehancuran dan kegagalan. Maka dari itu, jika engkau menjadi seorang pemimpin yang diberi amanah dan tanggung jawab, agar mampu memegang dan menjalankan sebaik-baiknya.

\section{Analisis Strategi Implementasi Pendidikan Karakter di TK Islam PAS Munqidzatun Nasyi'ah Wilangan.}

Untuk mengetahui strategi Implementasi pendidikan karakter di TK Islam PAS Munqidzatun Nasyi'ah Wilangan dikaji dengan pendapat Noeng Muhadjir. ${ }^{10}$ Metode yang digunakan adalah dengan menggunkan metode reflektif adalah gabungan dari metode induktif dan deduktif. Yakni mebelajarkan nilai dengan jalan memberikan konsep secara umum tentang nilai-nilai kebenaran kemudian melihatnya dalam kasus sehari-hari atau melihat dari kasus-kasus sehari-hari di kembalikan dalam kasus-kasus teoritisnya secara umum.

10 Zubaedi, Desain Pendidikan Karakter: Konsepsi dan Aplikasinya dalam Dunia Pendidikan (Jakarta: Kencana, 2011), 231-232. 
Hal ini dapat dibuktikan dengan adanya pemberikan penjelasan nilai-nilai moral kepada para siswa, setelah selesai tembang dolanan dinyanyikan baik didalam kelas sebelum pelajaran inti dimulai maupun menyanyikanya sambil bermain ditempat luas (halaman kelas).

\section{Analisis Hasil Pendidikan Karakter di TK Islam PAS Munqidzatun Nasyi’ah Wilangan.}

Hasil penanaman pendidikan karakter melalui kerifan lokal (Local Wisdom) berupa tembang dolanan di TK Islam PAS Munqidzatun Nasyi'ah Wilangan bisa dilihat dengan prilaku para siswa membuang sampah pada tempatnya dan saling mengucapkan salam serta bersalaman dengan ustadzustadzah maupun orang lain (tamu disekolah) ketika bertemu.

Selain yang disebut diatas, hasil penanaman pendidikan karater bisa dilihat dari hasiil observasi peneliti melihat beberapa siswa-siswi dari kelas B sedang menyirami bunga dengan asiknya mereka menyirami bunga tersebuat dengan mengambil air saling melimbang (meranting) sehingga tampak kerjasama yang sangat unik dari para siswa

Hal tersebut kalau kita kaji dengan pendapat Ratna Megawangi dengan mengunakan konsep sembilan nilai karakter yang perlu ditanamkan kepada peserta didik, yaitu:

1. Cinta Tuhan dan segenap ciptaan-Nya (love Allah, trust, reverevce, loyalty).

2. Kemandirian dan tanggung jawab (responsibility, excellence, self relience, discipline, orderliness).

3. Kejujuran/Amanah, Bijaksana (trustworthiness, reliability, honesty).

4. Hormat dan santun (respect, courtessy, obidience).

5. Dermawan, suka menolong dan gotong royong (love, compassion, caring, empathy, generousity, moderation, cooperetion).

6. Percaya diri, kreatif dan pekerja keras (confidence, assertiveness, creativity, resourcefulness, conrage, determination and enthusiasm).

7. Kepernimpinan dan keadilan (justice, fairness, mercy, leadership).

8. Baik dan rendah hati (kindness, friendness, humility, modesty). 
9. Toleransi dan kedamaian dan kesatuan (tolerance, flexibility, feacefulness, unity). ${ }^{11}$

Dilihat dari penjelasan diatas dapat digaris bahwa hasil dari pendidikan karakter di TK Islam PAS Munqidzatun Nasyi'ah Wilangan sudah memenuhi sembilan nilai karakter dasar yaitu:

a. Pada karakter hormat dan santun melalui saling mengucap salam dan berjabat tangan.

b. Kemandirian dan tanggung jawab ini bisa dilihat dari membuang sampah pada tempatnya.

\section{Penutup}

Berdasarkan hasil penelitian dan pembahasan yang telah diuraikan, maka dapat disimpulkan sebagai berikut:

1. Bentuk Pendidikan Karakter di TK Islam PAS Munqidzatun Nasyi'ah Wilangan adalah pendidikan karakter berbasis local widom (kearifan lokal) berupa tembang dolanan Jawa. Ada tiga tembang dolanan yang dipakai untuk penanaman karakter yaitu, Sluku-sluku Bathok, gundul-gundul Pachol dan Menthok-menthok.

2. Strategi implementasi pendidikan karakter di TK Islam PAS Munqidzatun Nasyi'ah Wilangan adalah menggunakan metode reflektif. Hal ini dapat dibuktikan dengan adanya pemberikan penjelasan nilai-nilai moral kepada para siswa

3. Hasil pendidikan karakter di TK Islam PAS Munqidzatun Nasyi' ah Wilangan sudah memenuhi niai-nilai karakter dasar yaitu: a). karakter hormat dan santun melalui saling mengucap salam dan berjabat tangan. b). Karakter kemandirian dan tanggung jawab ini bisa dilihat dari membuang sampah pada temapatnya.

\footnotetext{
${ }^{11}$ Ratna Megawangi, Pendidikan Karakter ..., 95.
} 


\section{Daftar Rujukan}

Basrowi. 2008. Memahami Penelitian Kualitatif. Jakarta: Rineka Cipta.

Dharma, Kesuma. 2011. Pendidikan Karakter Kajian Teori dan Praktik di Sekolah. Bandung: Remaja Rosdakarya.

Endraswara, Suwardi. 2005. Tradisi Lisan Jawa. Yogyakarta: Laksbang Presindo.

Gunawan, Heri. 2012. Pendidikan Karakter Konsep dan Implementasi. Bandung: Alfabeta.

Koesoema A, Doni. 2007. Pendidikan Karakter. Jakarta: PT Gramedia Widiasarana Indonesia.

Majid, Abdul. 2011. Pendidikan Karakter Persfektif Islam. Bandung: Remaja Rosdakarya.

Marimba, D. 1989. Pengantar Filsafat Pendidikan Islam. Bandung: Al-Ma'arif.

Masnur, Muslih. 2011. Pendidikan Karakter Menjawab Tantangan Krisis Multidimensional. Jakarta: Bumi Aksara.

Megawangi, Ratna. 2004. Pendidikan Karakter: Solusi yang Tepat untuk Membangun Bangsa. Jakarta: Star Energy.

Moleong, Lexy J. 2000. Metodologi Penelitian Kualitatif, Bandung: PT. Remaja Rosdakarya.

Mulyana, Deddy. 2004. Metodologi Penelitian Kualitatif. Bandung: Rosdakarya.

Nasional, Departemen Pendidikan. 2004. Kurikulum 2004, Standard Kompetensi Taman Kanak-kanak dan Raudatul Athfal. Jakarta: Direktorat Jenderal Pendidikan TK.

Nasional, Departemen Pendidikan. 2008. Kamus Besar Bahasa Indonesia. Jakarta: Balai Pustaka.

Padmo, Soekotjo. 1955. Ngengrengan Kasusastran Djawa. Jogjakarta: Hien Hoo Sing.

S. Nasution. 1996. Metode Penelitian Naturalistik Kualitatif. Bandung: Tarsito.

Spradley, James. P. 2007. The Etnographic Interview. Terjemahan Zulfa Eliza, Misbah.Yogyakarta: PT Tiara Wacana.

Sugiyono. 2006. Metode Penelitian Pendidikan: Pendekatan Kuantitatif, Kualitatif dan $R \& D$. Bandung: Alfabeta.

Thomas, Lickona. 1992. Educating For Character: How Our School Can Teach Respect and Responsibility. New York: Bantam Books.

Tri, Hariyanta Agung. 2012. Kamus Kebahasaan dan Kesusastraan. Surakata: Aksara Sinergi Media. 